\title{
Risk assessment method of coal and gas outburst based on T-S fuzzy neural network
}

\author{
ZHANG Yu ${ }^{1,}$ a, YANG Wen ${ }^{1, b}$, Yu Xinzhi ${ }^{1, c}$ Zhou Mingxuan ${ }^{1, d}$, Liu Chengpu ${ }^{1, e}$ \\ ${ }^{1}$ China University of Mining and Technology (Beijing) , Beijing, 100083 \\ a857873049@qq.com, b751334348@qq.com, c1134505040@qq.com, d554124184@qq.com, \\ e1132402351@qq.com
}

\begin{abstract}
Keywords: T-S fuzzy neural network; Coal and gas outburst; Risk assessment
Abstract. Based on coal and gas outburst factors, combined with single gas risk index and comprehensive evaluation method to select evaluation index, in order to evaluate coal and gas outburst, evaluation of coal and gas outburst is established t-s fuzzy neural network model. Combined fuzzy logic and neural network, the model is realized in matlab software fuzzy neural network building, training, so as to realize the purpose of network evaluation. A Case Study of Pingdingshan No.13 Mine to evaluate the danger of coal and gas outburst, the final forecasting result is the same as actual results and different methods to predict the results of other researchers, suggests that feasibility and rationality of T-S fuzzy neural network model, offers a new way for gas outburst risk assessment..
\end{abstract}

\section{Introduction}

Coal and gas outburst have a serious impact on the safe production of coal mine [1]. In coal mine production process, single measure method and complex index method for evaluation of coal and gas outburst [2-8]. Because coal and gas outburst are the result of many factors such as gas factors, coal structure, geological structure and mining conditions, there are obvious ambiguity. Therefore, fuzzy mathematics is widely used in the evaluation of gas outburst risk, but fuzzy mathematics is lack of self-learning ability and adaptive ability in the actual gas risk evaluation. TS fuzzy neural network not only can fully represent the fuzzy and qualitative knowledge, but also directly from the sample of complete and effective learning, parallel computing, fault tolerance and adaptive learning [9]. T-S fuzzy neural network is widely used in water quality evaluation, fault diagnosis and so on, but the method has less application in coal and gas outburst risk evaluation. Therefore, this paper applies the T-S fuzzy neural network model to assess the risk of coal and gas outburst in Pingdingshan No.13 Mine.

\section{T-S fuzzy neural network implementation}

T-S fuzzy neural network theory is a combination of fuzzy logic and neural networks. T-S fuzzy system not only has strong self-adaptability, but also has the function of automatically updating and constantly modifying membership function of fuzzy subset [10-11].

Based on the principle of T-S fuzzy neural network, fuzzy neural network gas outburst risk evaluation is realized in MATLAB R2013a programming [12].

\section{The selection of evaluation indicators}

The risk evaluation of gas outburst is based on the risk factors, single index, comprehensive evaluation index . The risk grade of gas is determined by certain mathematical model. According to the actual situation of coal mine safety production, "coal and gas outburst regulations", the coal and gas outburst risk rating is divided into three dangerous levels: \{I no outburst, II threaten outburst, III serious outburst\}.

Combined with the actual situation of Pingdingshan thirteen mines, the main factors affecting the coal and gas outburst in Pingdingshan No.13 Mine are the gas pressure, gas content, structural complexity, 
mining depth and other factors as the evaluation index, and increase the risk of gas outburst. The evaluation index is the initial velocity of coal gas and the solid coefficient of coal. The complexity of the structure is divided into three types according to the expert scoring method, the complexity is simple, relative complex and complex ( refer with: Tab.1).

Tab. 1 The complexity of the structure[13]

\begin{tabular}{cccc}
\hline $\begin{array}{c}\text { Complex range } \\
\text { of values }\end{array}$ & $\begin{array}{c}\text { Complexity of the } \\
\text { structure }\end{array}$ & Incidence & Effect Factors \\
\hline$[0,1)$ & simple & $\begin{array}{c}\text { No impact or less } \\
\text { impact } \\
\text { relative greater } \\
\text { impact } \\
{[1,2)}\end{array}$ & $\begin{array}{c}\text { Fault, fold, coal thickness and dip change, } \\
\text { bedding disorder, roof broken } \\
\text { Fault, fold, coal thickness and dip change, } \\
\text { bedding disorder }\end{array}$ \\
relative complex & greater influence & $\begin{array}{c}\text { Fault, fold, coal thickness and dip change, } \\
\text { bedding disorder, roof broken }\end{array}$ \\
\hline
\end{tabular}

\section{model data acquisition}

Using the uniform point distribution mode interpolate standard data (Coal and gas outburst grading evaluation criteria, refer with: Tab.2), and 296 samples were generated, 266 training samples were selected as the training data to train the fuzzy neural network, and 30 samples were used to test the fuzzy neural network. This method solved the problem that only the standard evaluation standard was used as the training sample, the prediction error is larger. The expected target for the training samples and test samples of level I is [0-3.5 ), the expected target range of training samples and test samples of level II is [3.5-5.5 ) , similarly, and the expected target for range of training samples and test samples of level III is [5.5- $+\infty][14]$.

Tab. 2 coal and gas outburst level evaluation criteria

\begin{tabular}{cccc}
\hline \multirow{2}{*}{ Evaluation index } & \multicolumn{3}{c}{ Level } \\
\cline { 2 - 4 } & $\mathrm{I}$ & $\mathrm{II}$ & $\mathrm{III}$ \\
\hline methane pressure & {$[0,0.66)$} & {$[0.66,0.74)$} & {$[0.74,3.0]$} \\
methane content & {$[0,4.0)$} & {$[4.0,8.0)$} & {$[8.0,15.0]$} \\
coal solidity coefficient & {$[0.8,2.0)$} & {$[0.5,0.8)$} & {$[0,0.5]$} \\
initial speed of methane emission & {$[0,0.6)$} & {$[6.0,10.0)$} & {$[10.0,30.0]$} \\
complexity of the structure & {$[0,1)$} & {$[1,2)$} & {$[2,3]$} \\
depth & {$[0,400)$} & {$[400,600)$} & {$[600,800]$} \\
\hline
\end{tabular}

\section{Parameter setting}

According to the dimension of training samples, the number of input-output nodes and fuzzy membership functions of fuzzy neural network are determined. The input data is 6-dimensional and the output data is 1-dimensional,that is, the structure of fuzzy neural network is 6-12-1, Which includes 12 membership functions, select 7 groups of coefficients p0-p6 fuzzy membership function center and the width of $\mathrm{c}$ and $\mathrm{b}$ randomly obtained. Learning rate xite $=0.001$; inertia coefficient alfa $=0.05$.

\section{Normalization processing}

The use of T-S fuzzy neural network for gas outburst evaluation requires normalization of the training samples and test samples and the measured 12 samples of the data. The realization of the normalized needs to call the MATLAB mapminmax function, so that the normalized data are in $[0,1]$, and retain the original number of relationships, after that use the anti-normalized method to restore the forecast data(refer with: Eq. 1).

$$
f: x \rightarrow y=\frac{x-x_{\min }}{x_{\max }-x_{\min }}
$$

In the formula, the normalized data is the maximum value and the minimum value, $\mathrm{y}$ is the normalized data, $\mathrm{x}$ is the original data, and $x_{\max }, x_{\min }$ is the maximum and minimum respectively.

\section{The establishment and testing of the model}

After the network node settings, coefficient initialization, parameter initialization, normalization of input network data, the network training is calculated by the fuzzy rule calculation, the network prediction calculation, the correction value of the coefficients $\mathrm{p}, \mathrm{b}, \mathrm{c}$, and then the training results 
were detected after detection, finally, according to predict the value of gas outburst to determine the risk level. Determination of hazard level of gas outburst is based on predictive value.

\section{Example Analysis}

\section{Overview of the study area}

Pingdingshan No.13 Mine Group Company (referred to as Pingdingshan No.13) is an annual production capacity of 2.0Mt coal large-scale coal mine. May 19, 2005, China Coal Research Institute of Fushun Branch evaluated Pingdingshan No.13 as coal and gas outburst mine. Since the construction of wells, there were three gas dynamic phenomenon, they occurred in the area of the B1, east wing of the B3 respectively,

\section{Gas risk assessment results}

Using the trained fuzzy neural network to evaluate the gas outburst risk of Pingdingshan No.13, the evaluation sample data (refer with: Tab.3), determination of hazard level of gas outburst is based on predictive value. In accordance with the training and testing of the expected target value, when the predicted value is less than 3.5, the gas outburst hazard level for the level I, When the predicted value is 3.5-5.5, the gas outburst hazard level is level II, and the prediction value is greater than 5.5, the hazard level is level III, as shown in Table 3.

Using the trained fuzzy neural network to evaluate the gas outburst risk of Pingdingshan No.13, the results (refer with: Fig.1). Of which 12051 wind tunnel samples, that is, No. 5-8 gas outburst hazard level for the level I, 11081 machine roadway sample, that is, No. 1-4 sample gas outburst hazard level for the level II, 13081 wind tunnel samples, that is, No. 6-8 gas outburst hazard level for the level III.

Tab.3 Sample data [15]

\begin{tabular}{|c|c|c|c|c|c|c|c|}
\hline Number & Place & $\begin{array}{l}\text { Methane } \\
\text { pressure }\end{array}$ & $\begin{array}{l}\text { Methane } \\
\text { content }\end{array}$ & $\begin{array}{l}\text { Initial speed } \\
\text { of methane } \\
\text { emission }\end{array}$ & $\begin{array}{c}\text { Coal } \\
\text { solidity } \\
\text { coefficient }\end{array}$ & $\begin{array}{c}\text { Complexity } \\
\text { of the } \\
\text { structure }\end{array}$ & Depth \\
\hline 1 & $\begin{array}{l}11081 \text { mechanical } \\
\text { roadway } 280 \mathrm{~m}\end{array}$ & 0.87 & 6.9 & 17.29 & 0.43 & 1.5 & 557 \\
\hline 2 & $\begin{array}{l}11081 \text { mechanical } \\
\text { roadway } 600 \mathrm{~m}\end{array}$ & 1 & 7.3 & 19.87 & 0.42 & 1.5 & 526 \\
\hline 3 & $\begin{array}{l}11081 \text { mechanical } \\
\text { roadway } 800 \mathrm{~m}\end{array}$ & 0.95 & 8.6 & 14.47 & 0.36 & 1.5 & 515 \\
\hline 4 & $\begin{array}{l}11081 \text { mechanical } \\
\text { roadway }\end{array}$ & 0.94 & 7.1 & 11.09 & 0.44 & 1.5 & 510 \\
\hline 5 & $\begin{array}{l}12051 \text { air lane } \\
\text { 300m }\end{array}$ & 0.9 & 5.4 & 9.05 & 0.67 & 1.4 & 449 \\
\hline 6 & $\begin{array}{l}12051 \text { air lane } \\
500 \mathrm{~m}\end{array}$ & 0.91 & 5.5 & 9.07 & 0.64 & 1.4 & 425 \\
\hline 7 & $\begin{array}{l}12051 \text { air lane } \\
700 \mathrm{~m}\end{array}$ & 0.94 & 4.74 & 7.51 & 0.7 & 1.4 & 385 \\
\hline 8 & $\begin{array}{l}12051 \text { air lane } \\
900 \mathrm{~m}\end{array}$ & 0.88 & 5.32 & 5.88 & 0.63 & 1.4 & 395 \\
\hline 9 & 13081 air lane $70 \mathrm{~m}$ & 2.1 & 11.4 & 5.84 & 0.65 & 2.2 & 709 \\
\hline 10 & $\begin{array}{l}13081 \text { air lane } \\
\text { 200m }\end{array}$ & 2.4 & 11.5 & 10.63 & 0.35 & 2.2 & 711 \\
\hline 11 & $\begin{array}{l}13081 \text { air lane } \\
323 \mathrm{~m}\end{array}$ & 2.3 & 13.2 & 24.06 & 0.39 & 2.2 & 720 \\
\hline 12 & $\begin{array}{l}13081 \text { air lane } \\
450 \mathrm{~m}\end{array}$ & 2.4 & 12.7 & 19.15 & 0.31 & 2.2 & 728 \\
\hline
\end{tabular}

The training prediction map and the testing data prediction map are generated, (refer with: Fig.2) , which include the actual output, the predicted output and the error. It can be seen that both the training data prediction and the test data predict the error between the actual output and the predicted output are relatively small. 


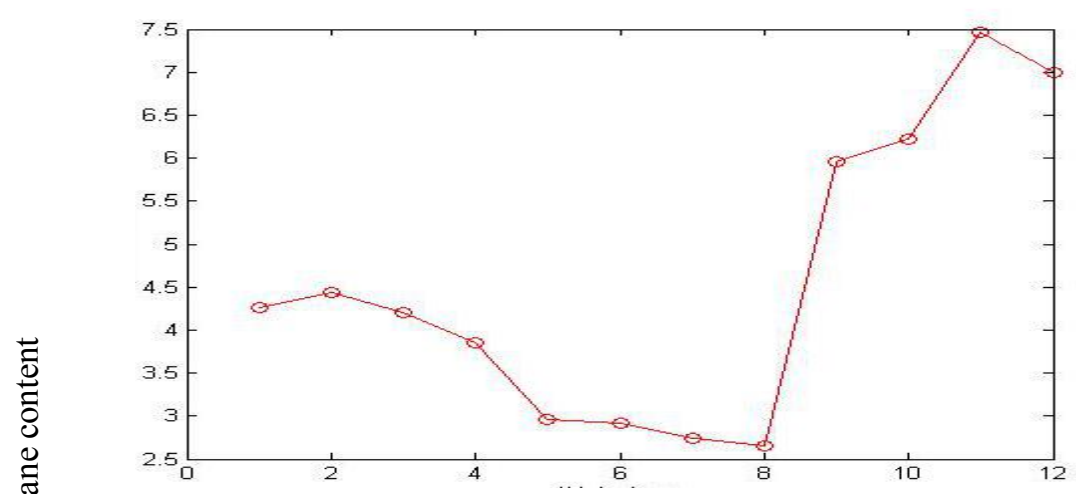

Fig1. Sample prediction

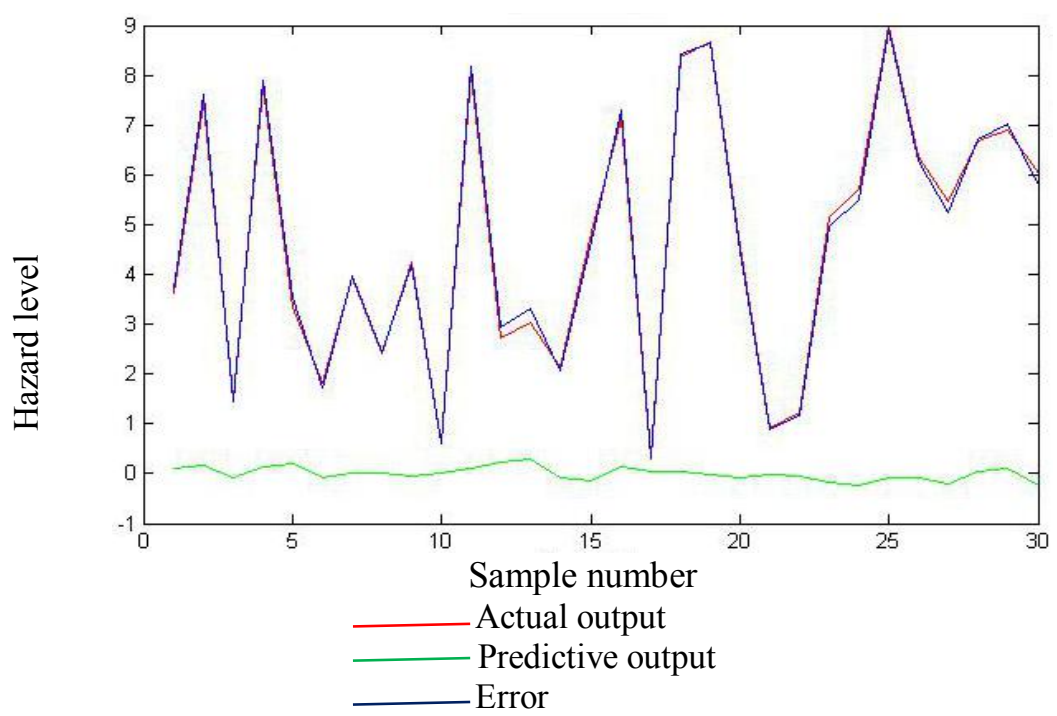

Fig 2. The testing data prediction

Tab.4 Comparison of evaluation results of coal and gas outburst

\begin{tabular}{|c|c|c|c|c|}
\hline Number & Place & $\begin{array}{c}\text { T-S fuzzy neural } \\
\text { network }\end{array}$ & $\begin{array}{c}\text { Extension } \\
\text { Clustering Method }\end{array}$ & $\begin{array}{l}\text { ANP-CE Network } \\
\text { Analysis and } \\
\text { Contact Entropy }\end{array}$ \\
\hline 1 & $\begin{array}{l}11081 \text { mechanical } \\
\text { roadway } 280 \mathrm{~m}\end{array}$ & II & \multirow{4}{*}{ threaten outburst } & \multirow{5}{*}{ threaten outburst } \\
\hline 2 & $\begin{array}{l}11081 \text { mechanical } \\
\text { roadway } 600 \mathrm{~m}\end{array}$ & II & & \\
\hline 3 & $\begin{array}{l}11081 \text { mechanical } \\
\text { roadway } 800 \mathrm{~m}\end{array}$ & II & & \\
\hline 4 & $\begin{array}{l}11081 \text { mechanical } \\
\text { roadway }\end{array}$ & II & & \\
\hline 5 & 12051 air lane $300 \mathrm{~m}$ & I & \multirow{4}{*}{ no outburst } & \\
\hline 6 & 12051 air lane $500 \mathrm{~m}$ & I & & \multirow{3}{*}{ no outburst } \\
\hline 7 & 12051 air lane $700 \mathrm{~m}$ & I & & \\
\hline 8 & 12051 air lane $900 \mathrm{~m}$ & I & & \\
\hline 9 & 13081 air lane $70 \mathrm{~m}$ & III & \multirow{4}{*}{ serious outburst } & \multirow{4}{*}{ serious outburst } \\
\hline 10 & 13081 air lane $200 \mathrm{~m}$ & III & & \\
\hline 11 & 13081 air lane $323 \mathrm{~m}$ & III & & \\
\hline 12 & 13081 air lane $450 \mathrm{~m}$ & III & & \\
\hline
\end{tabular}

Combined with the former extension cluster method [13] and ANP-CE network analysis and contact entropy analysis method[15] to Pingdingshan No.13of gas outburst risk evaluation results, found that three kinds of evaluation methods are basically the same, and the evaluation results (refer with: Tab.4). 


\section{Conclusions}

(1) Through the above research, it is indicated that T-S fuzzy neural network is feasible for gas outburst risk evaluation. Compared with other methods, it can generate more complex systems by a small number of fuzzy rules, so that the evaluation results are more objective.

(2) The accuracy of TS fuzzy neural network evaluation is relatively high, both the training data prediction and the test data prediction, the error between the actual output and the predicted output is relatively small, making the fuzzy logic and neural network to better play their respective and provide a new idea for the realization of gas risk assessment.

\section{References}

[1]Fan Tianji. Comprehensive technical manual for coal mine gas control [M].Jilin : Jilin audio visual publishing house,2003.

[2] Guo Deyong,Han Dexin, Wang Xinyi. Outburst-Prone Tectonophisical Environment and Its Applications[J]. Journal of University of Science and Technology Beijing ,2002, 24 (6): 581 -584.

[3] WU Qiang. Neural Network Model for Predicting Coal and Gas Outburst [J]. China Safety Science Journal,, 2001 (8): 69 -72.

[4] ZHANG Zi-xu,LIU Gao-feng, Li Run-sheng, ZHANG Jun. Regional forecast of coal and gas burst based on fuzzy pattern recognition [J].Journal of China Coal Society, 2007, 32 (6): 592 -595.

[5] GUO Deyong,LI Nianyou,PEI Dawen,ZHENG Dengfeng. Prediction method of coal and gas outburst using the grey theory and neural network [J]. Journal of University of Science and Technology Beijing, 2007, 29(4): 354 -357.

[6]Shi Biming. A fuzzy cluster analysis on the danger of coal and gas burst from coal seams [J]. Journal of Huainan mining institute, 1994, 14( 2) : 38- 43.

[7] Jiang Changyou. The coal seam outburst danger prediction of fuzzy comprehensive evaluation [J]. ZHONGZHOU COAL, 1997,(2) : 32- 33.

[8]Zhong Maohua,Dong Mingshan,Chen Baozhi. Neural Network Expert System for Risk Prediction of Coal Seams Outburst[J]. Journal of Xiangtan Mining Institute,1998,13(1):1-5.

[9] Zhou Zhongshou. The Application of Fuzzy Neural Network Based on T-S Model in Water Quality Evaluation[D].Nanjing:Hohai University,2007.

[10] Sun Zengqi, Xu Hongbing. Fuzzy-Neural Network Based On T-S Model[J]. Journal of Tsinghua University(Science And Technology),1997,37:76-80.

[11] Takagi T, SugenoM. Fzuzzy identification of systemsand itsalllicationtomodeling and control[J]. IEEETrans on Systems, Man, and Cybe-metworkics, 1985,15(1):116-132.

[12]SHI Feng, Wang Xiaochuan,YU Lei, LI Yang. Analysis of 30 Cases of MATLAB Neural Network [M].Beijing:Beihang University Press ,2010

[13] Guo Deyong, Zheng Maojie, Guo Chao, et al. Extension Clustering Method for Coal and Gas Outburst Prediction and Its Application[J]. Journal of China Coal Society,2009,06:783-787.

[14] Luo Dinggui, Wang Xuejun, Guo Qing. The Application of ANN Realized by MATLAB to Underground Water Quality Assessment[J]. Acta Scicentiarum Naturalum Universitis Pekinesis, 2004,40 (2) : 296-302.

[15] Nian Qifeng, Shi Shiliang, Li Runqiu. Study on Coal and Gas Outburst Prediction Based on Analytic Network Process and Connection Entropy[J]. Journal of Safety Science and Technology,2014,02:22-27 